\title{
PEMENUHAN HAK-HAK TENAGA KERJA PENYANDANG DISABILITAS YANG BEKERJA PADA YAYASAN DI BALI
}

\author{
Tjokorda Gde Agung Smara Raditia, Fakultas Hukum Universitas Udayana, e- \\ mail: smaracokde@gmail.com \\ Dewa Gede Pradnya Yustiawan, Fakultas Hukum Universitas Udayana, e-mail: \\ pradnya_yustiawan@unud.ac.id
}

doi: https://doi.org/10.24843/KS.2020.v08.i12.p02

\begin{abstract}
ABSTRAK
Penyandang disabilitas sering sekali kurang mendapat perhatian, seperti mendapat perlakuan yang berbeda atau diskriminasi. Kurangnya akses juga menjadi penghambat kehidupan seharihari para penyandang disabilitas. Harapan bagi para penyandang disabilitas untuk memperoleh pekerjaan bisa dikatakan kecil dibanding mereka yang tidak memiliki cacat fisik. Yayasan atau organisasi nirlaba dapat dikatakan memiliki peran kuat dalam menghadapi berbagai masalah yang tengah terjadi. Ketimpangan antara perkembangan pesat pariwisata Bali dengan pemenuhan hak-hak dasar dari kaum disabilitas telah mulai dijembatani melalui keberadaan yayasan atau organisasi nirlaba. Jenis penelitian ini adalah jenis penelitian hukum empiris, yaitu metode pendekatan yang digunakan untuk memecahkan suatu objek penelitian dengan cara meneliti data sekunder terhadap data primer yang ada dilapangan. Hasil studi menunjukkan perlakuan tenaga kerja penyandang disabilitas dalam Yayasan di Bali telah sesuai dengan peraturan yang berlaku dimana pihak Yayasan sudah melindungi dan mengakomodasi hak-hak pekerja penyandang disabilitas tanpa adanya diskriminasi dan perbedaan, seluruh peraturan perundangundangan telah diimplementasikan dengan baik oleh pihak yayasan guna memenuhi kebutuhan para pekerja penyandang disabilitas terutama pada dunia kerja.
\end{abstract}

Kata Kunci: Tenaga Kerja, Penyandang Disabilitas, Yayasan

\begin{abstract}
People with disabilities often receive less attention, different treatment, or discrimination. Limited access also becomes a barrier to their daily lives. They get smaller chances to get a job compared to those nondisabled. Foundations or non-profit organizations have a strong role in dealing with current issues. The organization has bridged the disparity between the rapid development of Bali tourism and the fulfillment of the basic rights of people with disabilities. The purpose of writing this journal is to determine the rights of workers with disabilities based on the prevailing laws and regulations in Indonesia and to find out the forms of treatment for workers with disabilities who work at foundations in Bali. This type of research is a type of empirical legal research, namely the approach method used to solve an object of research by examining secondary data against primary data in the field. The study results show the treatment received by workers with disabilities in a non-profit organization in Bali has been appropriate with the applicable regulations with the protection and accommodation of workers with disabilities without discrimination and differences. All laws and regulations have been implemented well by the foundation to meet the needs of workers with disabilities particularly in the world of work.
\end{abstract}

Keywords: Labor, People with Disabilities, Foundation 


\section{Pendahuluan}

\subsection{Latar Belakang}

Kelompok minoritas dimana-mana sangat dekat dengan perlakuan diskriminatif. Perilaku diskriminatif berupa perkataan atau perilaku. Sebagian dari minoritas yang ada adalah sekelompok penyandang disabilitas. Menurut Kamus Besar Bahasa Indonesia (KBBI), istilah disabilitas diartikan sebagai seseorang yang telah (menderita) sesuatu. Istilah disabilitas adalah istilah bahasa Indonesia yang berasal dari istilah bahasa Inggris untuk disabilitas (jamak: disables) yang artinya disabilitas atau Cacat. Penyandang disabilitas biasanya kurang mendapat perhatian, seperti perlakuan berbeda atau diskriminasi. Kurangnya kontak juga menjadi kendala dalam kehidupan sehari-hari para penyandang cacat. Dibandingkan dengan penyandang disabilitas fisik, ekspektasi penyandang disabilitas terhadap pekerjaan bisa dikatakan sangat kecil. Mencari pekerjaan penting bagi penyandang disabilitas, sama seperti kebutuhan dasar lainnya diantaranya pendidikan, kesejahteraan dan kenyamanan. ${ }^{1}$

Mengenai kondisi fisik seseorang, ada istilah yang disebut dengan PD Cacat. Menurut Undang-Undang Nomor 8 Tahun 2016, orang-orang yang terlibat Penyandang disabilitas, pada Bab 1 pasal 1 disebutkan bahwa penyandang disabilitas Setiap orang dinonaktifkan Keterbatasan fisik, intelektual, mental dan / atau sensorik Berinteraksi dengan lingkungan untuk waktu yang lama bisa dialami Hambatan dan kesulitan untuk partisipasi penuh dan efektif Nikmati hak yang sama dengan warga negara lain. PERDA Provinsi Bali menyatakan dalam Pasal 1 ayat 7 bahwa penyandang disabilitas adalah Setiap orang yang menderita penyakit, penyakit, kerusakan dan / atau Hilangnya fungsi tubuh internal, mental, intelektual atau sensorik Dalam jangka panjang, hal itu dapat menghambat partisipasi penuh dan efektif orang lain. Secara hukum. ${ }^{2}$

Penyandang disabilitas memiliki kedudukan, hak dan kewajiban yang sama dengan masyarakat non disabilitas. Sebagai bagian dari warga negara Indonesia, sudah sepantasnya penyandang disabilitas mendapatkan perlakuan khusus, yang dimaksudkan sebagai upaya perlindungan dari kerentanan terhadap berbagai tindakan diskriminasi dan terutama perlindungan dari berbagai pelanggaran hak asasi manusia. ${ }^{3}$ Meskipun sudah diatur dalam UU, hak penyandang disabilitas sampai sekarang masih sering mendapatkan perlakuan diskriminasi oleh perusahaan saat merekrut dan bahkan di tempPenyandang disablitas juga merupakan bagian dalam masyarakat yang berhak mendapatkan pekerjaan sesuai dengan tingkat kecacatannya, Bahkan Pasal 67 UU No. 13/2003 tentang Ketenagakerjaan menegaskan bahwa pengusaha yang memperkerjakan penyandang disabilitas wajib memberikan perlindungan yang sesuai dengan Tingkat kecacatan. Bahkan memasukkannya ke

1 Susiana, Susiana, and Wardah Wardah. "Pemenuhan Hak Penyandang Disabilitas Dalam Mendapatkan Pekerjaan Di BUMN." Law Reform 15, no. 2 (2019): 225-238.

2 Kusnawan, I. Gede, I. Gusti Ngurah Wairocana, and Ni Gusti Ayu Dyah Satyawati. "PENERAPAN PERATURAN DAERAH PROVINSI BALI NOMOR 9 TAHUN 2015 TENTANG PERLINDUNGAN DAN PEMENUHAN HAK PENYANDANG DISABILITAS DALAM PENERIMAAN TENAGA KERJA." Kertha Negara: Journal Ilmu Hukum, 1-7.

3 Ndaumanu, Frichy. "Hak Penyandnag Disabilitas: antara Tanggungjawab dan Pelaksanaan Oleh Pemerintah Daerah." Jurnal HAM 11, no. 1 (2020): 131-150. 
dalam Secara hukum, hak-hak penyandang disabilitas masih tersebar luas Perlakuan diskriminatif oleh perusahaan saat merekrut, Bahkan di tempat kerja. ${ }^{4}$

Perlindungan hukum bagi pekerja adalah perwujudan hak dasar dari konstitusi yang diatur yang melekat dan dilindungi olehnya Undang-Undang Dasar Negara Republik Indonesia Pasal 27 ayat (2) Pada tahun 1945. Di bidang sumber daya manusia, pekerja / buruh perlindungan hak mereka harus diberikan. Hak pekerja dalam UUTK yang diatur dalam Pasal 77 sampai dengan Pasal 101 adalah Meliputi hak buruh / pekerja. ${ }^{5}$ Banyak penyandang disabilitas termasuk Indonesia yang haknya dilanggar sehingga menikmati persamaan hak harus direalisasikan. Pasal 53 UndangUndang Penyandang Disabilitas Melindungi persamaan hak dan status penyandang disabilitas. Terendah Mencari pekerjaan, memiliki kesempatan pendidikan, Memiliki kesempatan yang sama di depan hukum. Penyandang disabilitas berhak mendapat kesempatan yang sama untuk memenuhi kebutuhan Self (kebutuhan dasar), sekalipun ada diskriminasi terhadap penyandang disabilitas Merupakan pelanggaran hak asasi manusia. ${ }^{6}$ Meskipun terdapat beberapa undang-undang dan peraturan pemerintah yang memberikan perlindungan hukum bagi penyandang disabilitas, namun penyandang disabilitas masih sulit memperoleh peluang di dunia kerja. Kalaupun ada, tidak mungkin untuk menentukan apakah semua hak penyandang disabilitas di dunia kerja sudah terwujud. Adanya yayasan tersebut dapat dimanfaatkan untuk menghilangkan berbagai tekanan dan batasan. Dapat dikatakan bahwa yayasan atau organisasi nirlaba memegang peranan penting dalam menangani berbagai permasalahan yang muncul. Kesenjangan antara pesatnya perkembangan pariwisata di Bali dengan realisasi hak-hak dasar penyandang disabilitas mulai dijembatani melalui keberadaan yayasan atau organisasi nirlaba. Yayasan sangat bertumpu pada sumber daya manusianya, sumber daya manusia, pekerja sosial, merupakan aset utama yang dibutuhkan yayasan karena mereka membuat dan menjalankan berbagai rencana pelayanan sesuai dengan visi dan tugas masing-masing.

\subsection{Rumusan Masalah}

Berdasarkan uraian latar belakang diatas, penulis mengangkat rumusan masalah yaitu:

1. Bagaimanakah pengaturan hak-hak tenaga kerja penyandang disabilitas berdasarkan Peraturan-perundang-undangan yang berlaku di Indonesia?

2. Bagaimanakah perlakuan yang diberikan yayasan terhadap tenaga kerja penyandang disabilitas di Bali?

\subsection{Tujuan Penelitian}

Tujuan penulisan jurnal ini adalah untuk mengetahui pengaturan hak-hak tenaga kerja penyandang disabilitas berdasarkan peraturan-perundang-undangan

4 Shaleh, Ismail. "Implementasi Pemenuhan Hak Bagi Penyandang Disabilitas Ketenagakerjaan Di Semarang." Kanun Jurnal Ilmu Hukum 20, no. 1 (2018): 63-82.

5 Hakim, Dani Amran, and Budi Ispriyarso. "Pemenuhan Hak-Hak Tenaga Kerja Melalui Penerapan Corporate Social Responsibility Pada Suatu Perusahaan (Studi Penerapan CSR Di PT. Great Giant Pineapple, Provinsi Lampung)." Law Reform 12, no. 2 (2016): 197-208.

6 Lestari, Eta Yuni, Slamet Sumarto, and Noorochmat Isdaryanto. "Pemenuhan hak bagi penyandang disabilitas di kabupaten Semarang melalui implementasi convention on the rights of persons with disabillities (CPRD) dalam bidang pendidikan." Integralistik 28, no. 1 (2017): 1-9. 
yang berlaku di Indonesia serta untuk mengetahui bentuk perlakuan terhadap tenaga kerja penyandang disabilitas yang bekerja pada Yayasan di Bali.

\section{Metode Penelitian}

Jenis penelitian ini adalah jenis penelitian hukum empiris, yaitu suatu metode yang pada dasarnya dirumuskan dan ditentukan oleh masyarakat dalam hukum, dan dibandingkan dengan melakukan pengecekan data sekunder terhadap data asli di lapangan. Data pokok dalam bidang ini digunakan untuk menyelesaikan objek penelitian yang artinya keberadaan hukum tidak dapat dipisahkan darinya. Kondisi sosial Perilaku sosial dan masyarakat terkait dengan sistem hukum. ${ }^{7}$ Secara umum, untuk penelitian hukum empiris, metode pendekatan yang tersedia mencakup peraturan perundang-undangan terkait dengan apa yang terjadi berdasarkan fakta, artinya memahami situasi sebenarnya dari lokasi penelitian dengan memeriksa semua peraturan perundang-undangan yang terkait dengan masalah tersebut. pengumpulan data dilakukan melalui teknik penelitian lapangan dan penelitian kepustakaan. Dalam penelitian lapangan, data diperoleh dengan cara menyebarkan kuesioner kepada responden yang menjadi sampel penelitian (dalam hal ini penyandang disabilitas yang bekerja di yayasan). Kuesioner ini merupakan teknik atau metode pengumpulan data tidak langsung (peneliti tidak akan langsung bertanya dan menjawab pertanyaan dengan responden). Responden diminta menjawab kuesioner yang sama, yang berisi serangkaian pertanyaan untuk mengungkapkan informasi tentang hak dan sistem kerja yang disediakan dan disediakan oleh yayasan. Wawancara juga dilakukan dengan menggunakan pedoman wawancara. Setelah data terkumpul dan di temukan hubungan terkait permasalahan yang dibahas dalam penelitian ini, selanjutnya data ini akan di analisa menggunakan analisa kualitatif.

\section{Hasil dan Pembahasan}

\subsection{Pengaturan hak-hak tenaga kerja penyandang disabilitas menurut Hukum Positif di Indonesia}

Perlindungan tenaga kerja bertujuan untuk memastikan Hak-hak dasar pekerja, jaminan kesetaraan dan Diskriminasi apa pun untuk mencapai kesejahteraan pekerja Dan keluarganya masih memperhatikan perkembangan Dunia bisnis dan kepentingan pengusaha. Penyandang disabilitas sering kali menghadapi diskriminasi, demikian pula penyandang disabilitas Sulit mencari pekerjaan. ${ }^{8}$ Peraturan perundang-undangan yang terkait dengan perlindungan tenaga kerja adalah Undang-Undang Nomor 13 Tahun 2003 tentang Ketenagakerjaan dan peraturan pelaksanaannya di bidang ketenagakerjaan.

Secara teori, perlindungan kerja dibagi menjadi tiga jenis berikut: ${ }^{9}$

1. Perlindungan sosial adalah perlindungan yang berkaitan dengan upaya masyarakat, tujuannya agar pekerja / buruh dapat menikmati dan mengembangkan kehidupannya seperti orang biasa, terutama sebagai

7 Soekanto, Soetjono, Pengantar Penelitian Hukum, Cetakan ke-3, (UI Press,Jakarta, 2006), 3.

8 Ak, I. Gede Siwananda Putra, I. Ketut Markeling, and I. Nyoman Darmadha. "PERLINDUNGAN HUKUM TERHADAP PEKERJA PENYANDANG DISABILITAS DI YAYASAN PUSPADI BALI." Kertha Semaya: Journal Ilmu Hukum 7, no. 8: 1-12.

9 Asyhadie, Zaeni, Hukum Kerja (Hukum Ketenagakerjaan Bidang Hubungan kerja), (PT. RajaGrafindo Persada, Jakarta, 2007), 78. 
anggota masyarakat dan anggota keluarga. Perlindungan sosial juga disebut kesehatan kerja.

2. Perlindungan teknis, yaitu jenis perlindungan yang terkait dengan bisnis Upaya melindungi pekerja atau buruh dari kecelakaan yang disebabkan oleh alat atau bahan kerja. Perlindungan semacam ini biasa disebut keselamatan kerja Yang dimaksud dengan perlindungan teknis meliputi keselamatan kerja, yaitu perlindungan terhadap pekerja atau buruh dari kemungkinan bahaya yang disebabkan oleh penggunaan alat atau bahan kerja.

3. Perlindungan ekonomi adalah jenis perlindungan yang berkaitan dengan upaya memberikan penghasilan yang cukup kepada pekerja atau pekerja untuk memenuhi kebutuhan sehari-hari mereka dan keluarganya, termasuk ketika pekerja atau pekerja tidak dapat bekerja karena alasan lain di luar kemauannya. Perlindungan ini biasa disebut jaminan sosial.

Menurut Undang-Undang Nomor 13 Tahun 2003 tentang Ketenagakerjaan, kontrak kerja atau perjanjian kerja adalah perjanjian antara pekerja / pekerja dengan pengusaha atau pemberi kerja yang memuat tentang kondisi kerja, hak dan kewajiban kedua belah pihak. Pasal 89 UU Ketenagakerjaan mengatur bahwa upah minimum ditetapkan oleh pemerintah sesuai dengan kebutuhan hidup yang layak dan memperhatikan produktivitas dan pertumbuhan ekonomi. Upah minimum dapat mencakup upah minimum menurut provinsi atau daerah / kota dan upah minimum menurut provinsi atau daerah / kota.

Penyandang disabilitas tunduk pada hukum, dan dalam hal ini mereka berhak melakukan perbuatan hukum. Oleh karena itu, sangatlah tidak beralasan jika undangundang atau kebijakan melarang penyandang disabilitas untuk berpartisipasi dalam kehidupan bermasyarakat, berbangsa, dan bernegara. Penyandang disabilitas sering dianggap tidak kompeten secara hukum, terutama saat mengambil tindakan hukum. Hal ini mencegah penyandang disabilitas untuk mendapatkan pekerjaan yang layak dan dapat kehilangan hak serta kemungkinan perlakuan yang tidak adil dalam kehidupan sosial. Pekerja penyandang disabilitas sendiri mendapatkan perlindungan hukum dalam Pasal 86 UU Ketenagakerjaan, yang mengatur bahwa setiap pekerja berhak untuk;

1. Keselamatan dan kesehatan kerja;

2. Moral dan kesusilaan;

3. Perlakuan yang sesuai dengan harkat dan manabat manusia serta nilai-nilai agama.

Dalam hal mendapatkan pekerjaan, Pasal 14 UU Penyandang Disabilitas juga menjamin hal tersebut. Undang-undang menetapkan bahwa kuota penyandang disabilitas adalah $1 \%$, artinya perusahaan wajib mempekerjakan satu penyandang disabilitas untuk setiap 100 karyawan. Pasal 5 UU tersebut juga mengatur: Setiap pekerja memiliki kesempatan yang sama untuk mendapatkan pekerjaan tanpa diskriminasi. Namun hal ini berbeda dengan fakta di lapangan dimana para penyandang disabilitas sulit bekerja di tempat atau perusahaan tempat mereka bekerja.

Perekrutan adalah proses mencari, mencari, mengundang dan mengejar Tentukan jumlah orang di dalam dan di luar perusahaan Sebagai tenaga kerja potensial dengan karakteristik tertentu Didefinisikan dalam rencana sumber daya manusia. Hasilnya adalah Apa yang didapat dari proses rekrutmen ada beberapa Masuk proses seleksi, proses penentuan calon yang mana Mana yang paling 
memenuhi syarat untuk posisi berikut perusahaan. ${ }^{10}$ Dasar untuk merekrut calon karyawan adalah Tentukan spesifikasi pekerjaan untuk posisi tersebut Memiliki. Beberapa dari mereka diposisikan sebagai karyawan, dan beberapa sebagai produsen Produk buatan tangan rakyat. Dalam hal ini pihak terkait merekrut dengan mengirimkan beberapa orang untuk melakukan supervisi langsung atau mencari penyandang disabilitas untuk langsung bekerja di yayasan. Selain mempekerjakan penyandang disabilitas, yayasan mereka juga membimbing penyandang disabilitas ke berbagai tempat kerja, termasuk restoran dan hotel. Ada beberapa penyandang disabilitas yang bekerja di yayasan, ada yang menjadi staf, dan ada pula yang produsen kerajinan tangan.

\subsection{Bentuk Perlakuan Terhadap Tenaga Kerja Penyandang Disabilitas Yang Bekerja Pada Yayasan Di Bali}

Sama seperti tenaga kerja lainnya, tenaga kerja disabilitas juga memperoleh perlakuan yang setara dengan seperti halnya perlindungan kerja dan pengupahan. Perlindungan kerja ini diperlukan untuk menjamin Hak-hak dasar pekerja dan jaminan perlakuan yang sama jika pekerja tidak ada Diskriminasi apa pun untuk mencapai kesejahteraan pekerja dan keluarganya masih memperhatikan perkembangan dunia bisnis dan kepentingan pengusaha. Adapun perlindungannya Dasar yang diberikan meliputi perlindungan sosial atau kesehatan kerja.

1. Kesehatan Kerja Bertujuan untuk melindungi atau melindungi karyawan dari situasi ini Hubungan kerja yang berbahaya bagi kesehatan dan moral mereka Dalam hal pekerjaan karyawan. Terfokus Tunjukkan semua energi dalam hubungan kerja Pekerjaan yang tidak memiliki hubungan kerja dengan pengusaha Tidak menerima perlindungan sosial yang ditentukan Dalam Bab 10 dari Hukum Ketenagakerjaan.

2. Perlindungan teknis atau keselamatan kerja. Landasan mencerminkan Lindungi keselamatan kerja dengan menciptakan lingkungan Pekerjaan yang dapat digunakan dan diakses dengan aman oleh staf Cacat selama pekerjaan dan kegiatan yayasan. Tiga Organisasi nirlaba terpantau, ada 29 orang Gangguan fisik berupa gerakan tangan dan kaki. biasanya Gunakan kruk, kursi roda untuk membantunya bergerak Dan prostesis.

3. Perlindungan ekonomis atau jaminan sosial. Walaupun penyelenggaraannya merupakan tanggung jawab dan kewajiban Negara, namun pihak yayasan sebagai penyedia kelja wajib memastikan bahwa setiap tenaga kerjaanya mendapatkan perlindungan jaminan sosial.

Gaji penyandang cacat merupakan kewajiban yayasan karena Hasil dari hubungan kerja adalah pembayaran upah atau gaji. Secara umum, upah adalah pembayaran yang dilakukan oleh pekerja selama hidup mereka Lakukan pekerjaan atau dianggap bekerja. Kekuatan seperti itu Pekerjaan para penyandang cacat bisa hidup normal dan diatur Perlindungan hukum atas upah sesuai dengan Pasal 27 (2) UUD 1945 yaitu: Setiap warga negara berhak atas pekerjaan penghidupan yang layak bagi kemanusiaan. Pasal ini dapat dimaknai bahwa negara bertanggung jawab terhadap hak konstitusional warga.

Pasal ini dijabarkan lebih lanjut dalam UU Ketenagakerjaan yaitu pada Pasal 88 ayat (1): setiap pekerja/buruh berhak memperoleh penghasilan yang memenuhi

10 Uwiyono, Aloysius, dkk, Asas-Asas Hukum Perburuhan, (PT. RajaGrafindo Persada, Jakarta, 2014), 23. 
penghidupan yang layak bagi kemanusiaan. Yang artinya memperoleh penghasilan hidup Yang layak adalah pendapatan pekerjaan atau jumlah pendapatan berdasarkan hasil Pekerjaan dapat memenuhi kebutuhan hidup / pekerja / pekerja, dan Cara keluarga yang masuk akal, termasuk makanan, pakaian, Perumahan, pendidikan, perawatan kesehatan, hiburan dan tabungan hari tua. Kebijakan gaji yang diterapkan oleh yayasan adalah sebagai berikut pengikut.Tetapkan kebijakan pengupahan, termasuk struktur dan Menurut tingkat gaji dari kemampuan dan tanggung jawab pekerjaan, Upah lembur, bayar untuk ketidakhadiran karena ketidakhadiran, Gaji karena tidak dapat bekerja karena aktivitas lain di luar Perhitungan umum pekerjaan dan pemotongan gaji Upah dilakukan setelah mendapat persetujuan dari manajemen Pengawasan oleh direksi dan dewan pengawas serta pengawasan oleh direksi Direktur Yayasan. Gaji sangat penting Penting untuk merumuskan anggaran yayasan sebagaimana adanya Seperti kita ketahui bersama, yayasan sangat bergantung pada donator.

Upah minimum tergantung pada provinsi atau wilayah Daerah / kota menentukan upah minimum membantu yayasan dalam menyusun anggaran tahunan upah minimum (dikeluarkan oleh instansi terkait) pemerintah daerah bisa dijadikan referensi dan mencari para donatur untuk memahami tenaga kerja cacat ini harus dihargai melalui pekerjaan gajinya tidak dapat disangkal bahwa ini biasanya persalinan penyandang disabilitas yang bekerja di sektor sosial atau nirlaba dipertimbangkan sebagai relawan gaji tidak diperhitungkan dengan cermat dan profesional. karena itu, adanya standar upah membantu yayasan advokasi hak-hak penyandang disabilitas.

\section{Kesimpulan}

Perlakuan tenaga kerja penyandang disabilitas pada yayasan di Bali telah sesuain dengan peraturan yang berlaku dimana pihak Yayasan sudah melindungi dan mengakomodasi hak-hak pekerja penyandang disabilitas tanpa adanya diskriminasi dan perbedaan, seluruh peraturan perundang-undangan telah diimplementasikan dengan baik oleh pihak yayasan guna memenuhi kebutuhan para pekerja penyandang disabilitas terutama pada dunia kerja. Pihak yayasan agar lebih meningkatkan beberapa fasilitas pendukung bagi para tenaga kerja penyandang disabiltas dan juga yayasan dapat untuk meneruskan upaya pemerataan hak kerja bagi penyandang disabilitas kemudian untuk pemerintah agar lebih memperhatikan para pekerja penyandang disabilitas dan membantu menyediakan sebagian fasilitas yang dibutuhkan.

\section{Daftar Pustaka}

Buku:

Asyhadie, Zaeni, Hukum Kerja (Hukum Ketenagakerjaan Bidang Hubungan kerja), (PT. RajaGrafindo Persada, Jakarta, 2007).

Rusli, Hardijan, Hukum Ketenagakerjaan, (Ghalia Indonesia, Bogor, 2011).

Soekanto, Soetjono, Pengantar Penelitian Hukum, Cetakan ke-3, (UI Press,Jakarta, 2006).

Uwiyono, Aloysius, dkk, Asas-Asas Hukum Perburuhan, (PT. RajaGrafindo Persada, Jakarta, 2014).

\section{Jurnal:}

Ndaumanu, Frichy. "Hak Penyandnag Disabilitas: antara Tanggungjawab dan Pelaksanaan Oleh Pemerintah Daerah." Jurnal HAM 11, no. 1 (2020): 131-150. 
Hakim, Dani Amran, and Budi Ispriyarso. "Pemenuhan Hak-Hak Tenaga Kerja Melalui Penerapan Corporate Social Responsibility Pada Suatu Perusahaan (Studi Penerapan CSR Di PT. Great Giant Pineapple, Provinsi Lampung)." Law Reform 12, no. 2 (2016): 197-208.

Shaleh, Ismail. "Implementasi Pemenuhan Hak Bagi Penyandang Disabilitas Ketenagakerjaan Di Semarang." Kanun Jurnal Ilmu Hukum 20, no. 1 (2018): 63-82.

Kusnawan, I. Gede, I. Gusti Ngurah Wairocana, and Ni Gusti Ayu Dyah Satyawati. "PENERAPAN PERATURAN DAERAH PROVINSI BALI NOMOR 9 TAHUN 2015 TENTANG PERLINDUNGAN DAN PEMENUHAN HAK PENYANDANG DISABILITAS DALAM PENERIMAAN TENAGA KERJA." Kertha Negara: Journal Ilmu Hukum, 1-7.

Lestari, Eta Yuni, Slamet Sumarto, and Noorochmat Isdaryanto. "Pemenuhan hak bagi penyandang disabilitas di kabupaten Semarang melalui implementasi convention on the rights of persons with disabillities (CPRD) dalam bidang pendidikan." Integralistik 28, no. 1 (2017): 1-9.

Pawestri, Aprilina. "Hak Penyandang Disabilitas dalam Perspektif HAM Internasional dan HAM Nasional." Era Hukum-Jurnal Ilmiah Ilmu Hukum 15, no. 1 (2017).

Ak, I. Gede Siwananda Putra, I. Ketut Markeling, and I. Nyoman Darmadha. "PERLINDUNGAN HUKUM TERHADAP PEKERJA PENYANDANG DISABILITAS DI YAYASAN PUSPADI BALI." Kertha Semaya: Journal Ilmu Hukum 7, no. 8: 1-12.

Putra, Pamungkas Satya. "Aksesibilitas Perlindungan Hukum Bagi Tenaga Kerja Penyandang Disabilitas di Kabupaten Karawang." Mimbar Hukum-Fakultas Hukum Universitas Gadjah Mada 31, no. 2 (2019): 205-221.

Suyanto, Heru, and Andriyanto Adhi Nugroho. "Perlindungan Hukum terhadap Hakhak Pekerja Outsourcing Berdasarkan Asas Keadilan." Jurnal Yuridis 3, no. 2 (2017): 61-74.

Susiana, Susiana, and Wardah Wardah. "Pemenuhan Hak Penyandang Disabilitas Dalam Mendapatkan Pekerjaan Di BUMN." Law Reform 15, no. 2 (2019): 225-238.

\section{PERATURAN PERUNDANG-UNDANGAN}

Indonesia, Undang-Undang Dasar Negara Republik Tahun 1945.

Indonesia, Undang-Undang Tentang Ketenagakerjaan, Nomor 13 Tahun 2003, (Lembaran Negara Republik Indonesia Nomor 39 Tahun 2003, Tambahan Lembaran Negara Republik Indonesia Nomor 4279).

Indonesia, Undang-Undang Tentang Penyandang Disabilitas, Nomor 8 Tahun 2016, (Lembaran Negara Republik Indonesia Nomor 69 Tahun 2016, Tambahan Lembaran Negara Republik Indonesia Nomor 5871).

Peraturan Daerah Provinsi Bali Nomor 9 Tahun 2015 Tentang Perlindungan Dan (Pemenuhan Hak Penyandang Disabilitas, Lembaran Daerah Provinsi Bali Nomor 9 Tahun 2015, Tambahan Lembaran Daerah Provinsi Daerah Bali Nomor 7). 